\title{
Assessment of the hematological profile in neonates borne to sever pre eclamptic mothers (single center study)
}

\begin{abstract}
Background: Preclampsia is a common disease unique to human pregnancy representing a challenge to obstetricians and neonatologists because of its serious effects on the mothers and babies. We aimed to evaluate hematological and coagulation aspects in newborns of preeclamptic mothers
\end{abstract}

Patients and methods: Sixty (30 full and 30 preterm) neonates delivered to hypertensive mothers and another 30(15 full term and 15 preterm) babies of healthy normotensive mothers were as controls were enrolled. Detailed history taking and full clinical examination were done stressing on parity, mode of delivery, birth weight, APGAR score at o and five minutes and gestational age. All enrolled neonates were subjected to complete blood count (HB, HT, MCV, MCH, WBCS, PLATES), PT, PC and PTT.

Results: In full term babies of preeclamptic mothers, primigravida were $70 \%$ compared to $20 \%$ in controls while In preterm group, prmigravida mothers were $80 \%$ compared to $33.3 \%$ in controls $(\mathrm{p}=0.001)$. Cesarean section was the predominant mode of delivery in preterm neonates to preclamptic mothers $(76.6 \%$ compared to $13.3 \%$ in controls while in full term group, cesarean section was $53.3 \%$ compared to $86.3 \%$ for the controls. Sever preeclampsia comprised $80 \%$ of mothers of pre term infants versus $33.3 \%$ in mothers of term infants APGAR score was lower in infant of preclamptic mothers. RBCs number were and hemoglobin levels were significantly higher in neonates of preclamptic mothers (either term or preterm) than the control $(\mathrm{p}=0.001)$ while WBCs were significantly lower in neonates of preclamptic mothers $(10.7 \pm 2.1,10.8 \pm 2.2$ and $13.1 \pm 1.9,13 \pm 1.7$ respectively) $(\mathrm{p}=0.001)$.

Platelets numbers were significantly low in cases $(186.1 \pm 91.5,133.7 \pm 58.9)$ and 223.1 \pm 43.4 and $216.4 \pm 51.8$. Coagulation profile is significantly impaired PT, PTT $28.03 \pm 6.9$, $21.7 \pm 3.1 \mathrm{in}$ cases and $14.1 \pm 1.8$ and $13.4 \pm 1.5$ in controls $(\mathrm{p}=0.001)$. Prothrombin concentration was significantly lawer in cases $(43.21 \pm 78,61 \pm 7.7)$ compared to controls $(70 \pm 3.5,74.2 \pm 1.9)$.

Conclusion: Neonates borne to preeclamptic mothers are more susceptible to impaired global coagulation status which is more expressed in preterm babies.
Volume 4 Issue $6-2018$

\author{
Madiha Abdalla El Sayed,' Amir Ahmed \\ Abdalla ${ }^{2}$ \\ 'Pediatric department, Mina University, Egypt \\ ${ }^{2}$ Mina University, El Minya, Egypt
}

Correspondence: Amir Ahmed Abdalla, Assistant professor of obstetrics and gynecology, faculty of medicine, Mina University, El Minya, Egypt, Email ameerelsherief@yahoo.com

Received: November 13, 2018 | Published: December 19, 2018

\section{Introduction}

Hypertensive disorders during pregnancy are associated with high maternofetal mortality and morbidity in both underdeveloped and developed countries. ${ }^{1}$ Approximately $70 \%$ of hypertensive disorders

are due to gestational hypertension this condition is called pre eclampsia. ${ }^{2}$ The working group of national High Blood Education Program (NHBPEP) had classified these disorders into five types. ${ }^{3}$

a. Gestational hypertension (formerly pregnancy-induced hypertension that included transient hypertension)

b. Preeclampsia.

c. Eclampsia.

d. Preeclampsia superimposed on chronic hypertension.

e. Chronic hypertension.

These disorders complicating $10-15 \%$ of all pregnancies however this ratio suspected to be higher in underdeveloped counties for many reasons such as lack of antenatal care, absence of health awareness and low socioeconomic status. ${ }^{4,5}$ Preclampsia is usually associated with several fetal and neonatal complications such as fetal distress, fetal death, growth restriction, oligohydramnios, low APGAR scores and preterm delivery. ${ }^{6}$ The increased incidence of perinatal morbidity and mortality seen in pregnancies complicated by preeclampsia, although complex and multifactorial, is primarily due to the need for premature delivery and utero-placental insufficiency resulting in compromises of fetal blood flow. ${ }^{7,8}$

A wide range of blood changes usually associated with normal uncomplicated pregnancy, namely neutrophilic leukocytosis, hyperlipidemia and procoagulant, hypofibrinolytic changes. Preeclampsia has been found to enhance these normal changes and also cause placental abnormalities resulting in both fetal and neonatal complications ${ }^{9,10}$ hence we need to evaluate some of these hematological changes in babies of preeclamptic mother in order early recognition and managements.

\section{Patients and method}

This prospective case control study was conducted at Minia University obstetric and children's Hospital El Minya, Egypt, for duration of 8 months (August 2016 to April 2017). The study was conducted according to the principles of Helsinky and was approved 
by the research ethical committee of faculty of medicine, Minia University and approved written consents were obtained from the mothers enrolled in the study. The study included 60 cases and 60 controls. Case group included the neonates born to pregnant Pre eclamptic mothers while control group enrolled healthy gestational age matched neonates borne to healthy mothers. Preeclampsia is defined as a) hypertension with proteinuria (systolic pressure elevated $>140 \mathrm{~mm}$ of $\mathrm{Hg}$ and diastolic pressure $>90 \mathrm{~mm}$ of $\mathrm{Hg}$ appearing for the first time after 20 weeks of gestation b) proteinuria alone ( $>300 \mathrm{mg} / 24$ hour). Babies born with high maternal or neonatal risk factors like, diabetes mellitus, severe anemia, chronic hypertension, renal disease, heart disease, connective tissue disease, babies born to mothers with hypertension diagnosed before 20 weeks of gestation and babies with congenital malformations all were excluded from the study (Table 1).
Patient group involved 30 full term and 30 preterm neonates and control group enrolled 30 full term and 30 preterm ones. Detailed maternal history, prenatal, natal and postnatal history was obtained. Thorough clinical examination of the neonates was done. Anthropometric parameters like head circumference, chest circumference, length, weight, and were recorded. Immediately after birth and at $72 \mathrm{~h}$ after birth $2 \mathrm{ml}$ cord blood was collected into the vaccutainer anticoagulated with EDTA and following parameters were studied. Neonatal CBC count and the red cell indices - MCV, $\mathrm{MCH}$, and $\mathrm{MCHC}$ were estimated using 5 part Sysmex Automated cell analyzer. Coagulation profile like PT, PTT was estimated. Severe preclampsia is defined as diastolic blood pressure (BP) of at least 110 $\mathrm{mm} \mathrm{Hg}$ or systolic BP of at least $160 \mathrm{~mm} \mathrm{Hg}$, and/or symptoms, and/ or biochemical and/or hematological impairment (Table 2). ${ }^{11}$

Table I Demographic and clinical data of precamptic mothers as well as of healthy controls

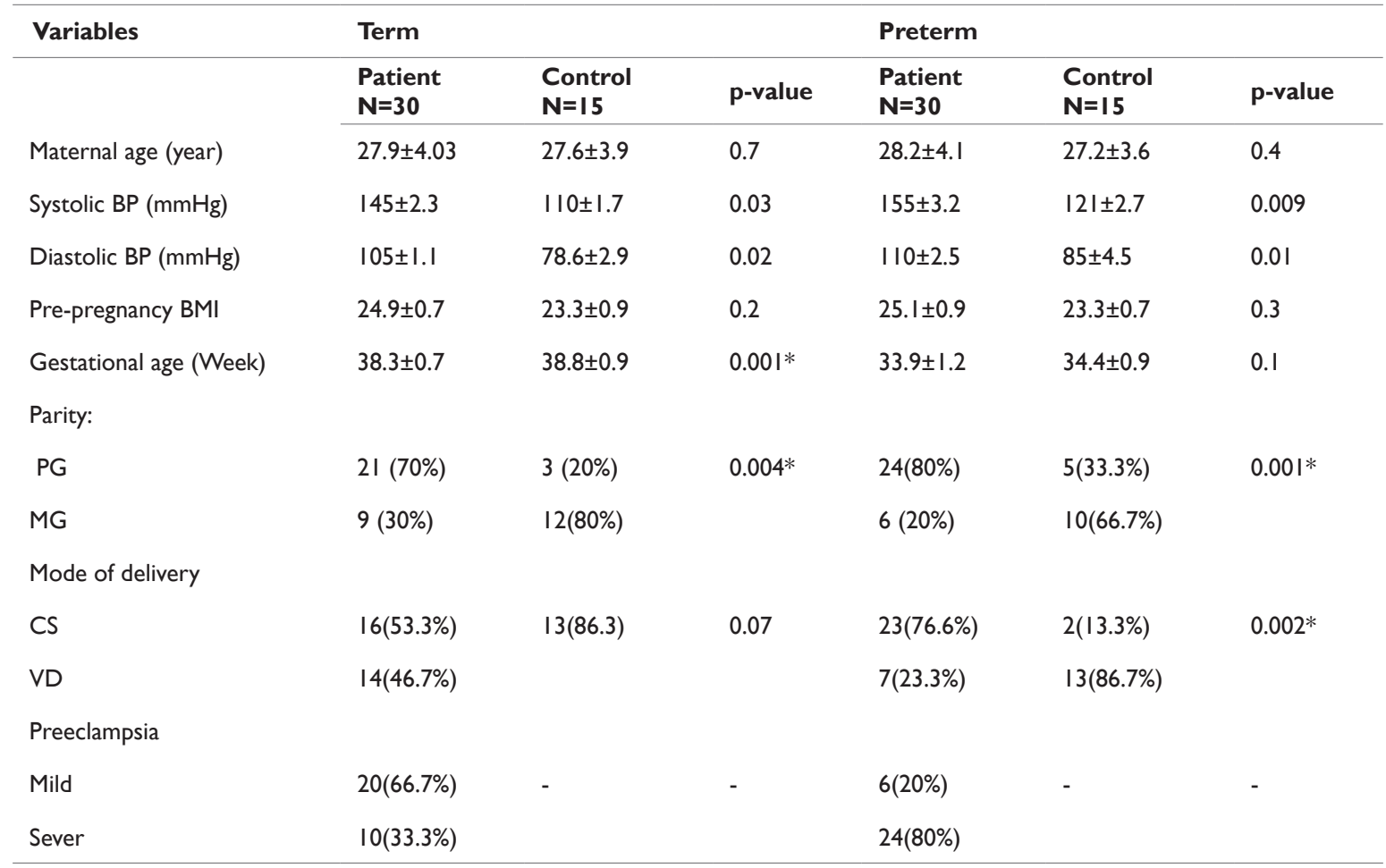

BP, blood pressure; PG, primigravida; MG, multigravida; CS, cesarean section;VD, vaginal delivery; BMI, body mass index; *, significant ( $P<0.05$ ).

Table 2 Clinical data of infant of preeclampsia as well as healthy controls

\begin{tabular}{|c|c|c|c|c|c|c|}
\hline \multirow[t]{2}{*}{ Variables } & \multicolumn{3}{|c|}{ Full term } & \multicolumn{3}{|l|}{ Preterm } \\
\hline & $\begin{array}{l}\text { Patient } \\
\mathbf{N}=30\end{array}$ & $\begin{array}{l}\text { Control } \\
N=15\end{array}$ & p-value & $\begin{array}{l}\text { Patient } \\
\mathrm{N}=30\end{array}$ & $\begin{array}{l}\text { Control } \\
N=15\end{array}$ & p-value \\
\hline Birth weight (kg) & $2.2 \pm 0.2$ & $3.1 \pm 0.1$ & $0.00 I^{*}$ & $1.8 \pm 0.2$ & $2.2 \pm 0.1$ & $0.001 *$ \\
\hline APGAR (I minute) & $7.7 \pm 0.8$ & $8.8 \pm 0.7$ & $0.001 *$ & $6.5 \pm 0.7$ & $7.4 \pm 0.3$ & $0.001 *$ \\
\hline APGAR (5 minute) & $8.3 \pm 0.6$ & $9.5 \pm 0.5$ & $0.00 I^{*}$ & $7.5 \pm 0.9$ & $8.5 \pm 0.8$ & $0.001 *$ \\
\hline \multicolumn{7}{|l|}{ Hematocrit value } \\
\hline $\mathrm{Hb}(\mathrm{gm} / \mathrm{ml})$ & $16.2 \pm 0.9$ & $15.4 \pm 0.8$ & $0.004^{*}$ & $16.6 \pm 1.1$ & $15.1 \pm 0.5$ & $0.001 *$ \\
\hline $\mathrm{MCV}$ & $89.1 \pm 2.2$ & $91.6 \pm 3.1$ & 0.67 & $82.1 \pm 3.2$ & $89.6 \pm 1.1$ & 0.77 \\
\hline $\mathrm{MCH}$ & $24.1 \pm 1.8$ & $23.9 \pm 1.9$ & 0.78 & $25.1 \pm 2.7$ & $24.9 \pm 1.9$ & 0.68 \\
\hline
\end{tabular}




\begin{tabular}{|c|c|c|c|c|c|c|}
\hline \multirow[t]{2}{*}{ Variables } & \multicolumn{3}{|l|}{ Full term } & \multicolumn{3}{|l|}{ Preterm } \\
\hline & $\begin{array}{l}\text { Patient } \\
\mathrm{N}=30\end{array}$ & $\begin{array}{l}\text { Control } \\
\mathrm{N}=15\end{array}$ & p-value & $\begin{array}{l}\text { Patient } \\
\mathbf{N}=30\end{array}$ & $\begin{array}{l}\text { Control } \\
N=15\end{array}$ & p-value \\
\hline $\mathrm{MCHC}$ & $32.7 \pm 3.3$ & $33.8 \pm 4.1$ & 0.67 & $32.7 \pm 1.3$ & $34.8 \pm 1.1$ & 0.67 \\
\hline RBCs $(106 / \mathrm{ml})$ & $4.6 \pm 0.4$ & $3.6 \pm 0.2$ & $0.001 *$ & $4.7 \pm 0.4$ & $3.8 \pm 0.4$ & $0.001 *$ \\
\hline WBCs $(103 / \mathrm{ml})$ & $10.7 \pm 2.1$ & $13.1 \pm 1.9$ & $0.001 *$ & $10.8 \pm 2.2$ & $13.8 \pm 1.7$ & $0.001 *$ \\
\hline Plateletcount (109/L) & $|86| \pm 9 \mid .5$. & $223.1 \pm 43.4$ & $0.00 I^{*}$ & $133.7 \pm 58.9$ & $216.4 \pm 51.8$ & $0.001 *$ \\
\hline PT (second) & $28.03 \pm 6.9$ & $\mid 4.1 \pm 1.8$ & 0.001 & $21.7 \pm 3.1$ & $13.4 \pm 1.5$ & $0.001 *$ \\
\hline PC (\%) & $43.2 \pm 7.8$ & $70 \pm 3.5$ & 0.001 & $61 \pm 7.7$ & $74.2 \pm 19$ & $0.001 *$ \\
\hline PTT (second) & $52.9 \pm 6.7$ & $50.3 \pm 2.6$ & 0.003 & $51.2 \pm 9.7$ & $31.8 \pm 6.5$ & $0.001 *$ \\
\hline
\end{tabular}

$\mathrm{Hb}$, hemoglobin; MCV, mean corpuscular volume; $\mathrm{MCH}$, mean corpuscular hemoglobin; $\mathrm{MCHC}$, mean corpuscular hemoglobin concentration; RBCs, red blood cells;WBCs, white blood cells; PT, prothrombin time; PC, prothrombin concentration; PTT, partial thromboplastin time; *, significant ( $<<0.05)$.

\section{Statistical analysis}

Data was entered into Microsoft excel data sheet and was analyzed using SPSS 22.0 version software. Numerical data were expressed as means while non numeric data were expressed as frequencies. The differences between two groups were compared using independent student $t$ test. $P$ value $<0.05$ was considered as statistically significant.

\section{Results}

Mother of hypertensive term babies were $70 \%$ primigravida while in control group $20 \%$. In preterm group primigravida mothers were $80 \%$ while the in the control was $33.3 \%(\mathrm{p}=0.001)$. Cesarean section was the predominant mode of delivery in in hypertensive mother of the preterm babies $76.6 \%$ compared to $13.3 \%$ in control group. In full term group cesarean section was $53.3 \%$ compared to $86.3 \%$ for the controls. Sever preeclampsia comprised $80 \%$ of mothers of preterm infants and $33.3 \%$ of mothers of term infants APGAR score was low in preeclamptic group . $\mathrm{RBCs}$ number and $\mathrm{Hb}$ content was significantly high in neonates preeclamptic groups than the either term or preterm $(16.2 \pm 0.9,16.6 \pm 1.1)$ than the control $(15.4 \pm 0.8,15,1 \pm 0.5)$,WBCs were significantly low in preeclamptic groups mean $(10.7 \pm 2.1,10.8 \pm 2.2)$ and $(13.1 \pm 1.9,13 \pm 1.7)$ respectively $(\mathrm{p}=0.001)$. Platelets numbers were significantly low in cases $(186.1 \pm 91.5,133.7 \pm 58.9)$ compared to $223.1 \pm 43.4$ and $216.4 \pm 51.8$ in control group. Coagulation profile was significantly impaired. PT, PTT were $28.03 \pm 6.9,21.7 \pm 3.1$ in cases and $14.1 \pm 1.8$ and $13.4 \pm 1.5(\mathrm{p}=0.001)$ prothrombin concentration was significantly law in cases $(43.21 \pm 78,61 \pm 7.7)$ compared to controls $(70 \pm 3.5,74.2 \pm 1.9)$. Term newborn were more brought via cesarean section than preterm babies the percentage of sever preeclampsia was significantly higher in full term babies $(80 \%)$ and $(33.3 \%)$ in preterm $(\mathrm{p}=0.001)$. HB value and RBCs numbers were significantly high in preterm neonates while WBCs and Platelets were significantly low in the same group $(\mathrm{p}=0.001) \mathrm{PT}$ was prolonged and $\mathrm{PC}$ is decreased (Table 3).

Table 3 Comparison between term and preterm preeclampsia according to mother data

\begin{tabular}{llll}
\hline Variables & $\begin{array}{l}\text { Term } \\
\text { preeclampsia } \\
\mathbf{N}=30\end{array}$ & $\begin{array}{l}\text { Preterm preeclampsia } \\
\mathbf{N}=30\end{array}$ & p-value \\
\hline Mother age (year) & $28.2 \pm 4.1$ & $27.9 \pm 4.03$ & 0.7 \\
Pre-pregnancy BMI & $25.1 \pm 0.9$ & $24.9 \pm 0.7$ & 0.2 \\
Pregnancy duration & $33.9 \pm 1.2$ & $38.3 \pm 0.7$ & $0.00 I^{*}$ \\
Parity & & & 0.7 \\
PG & $20(66.7 \%)$ & $21(70 \%)$ & \\
MG & $10(33.3 \%)$ & $9(30 \%)$ & $0.002^{*}$ \\
Mode of delivery & & & \\
CS & $23(76.7 \%)$ & $16(53.3 \%)$ & \\
NVD & $7(23.3 \%)$ & $14(46.7 \%)$ & $0.001 *$ \\
Preeclampsia & & & \\
Mild & $6(20 \%)$ & $20(66.7 \%)$ & \\
Sever & $24(80 \%)$ & $10(33.3 \%)$ & \\
PROM & - & $3(10 \%)$ & \\
Chorioamniontis & $3(10 \%)$ & $3(10 \%)$ & \\
\hline
\end{tabular}

PG, primigravida; MG, multigravida; $C S$, cesarean section; NVD, normal vaginal delivery; PROM, premature rupture of membrane; *, significant ( $P<0.05$ ). 


\section{Discussion}

Pregnancy induced hypertension one of the important causes of maternal and neonatal mortality and morbidity. ${ }^{12}$ Several types of complications had been documented among those babies born to hypertensive mothers..$^{13}$ One of these problems is the hematological changes which may add to the existing neonatal morbidities. There was significant increase in $\mathrm{Hb}$ level and RBCs count in the study neonates compared to controls $(\mathrm{p}=0.004,0.001)$ respectively agreeing the results of Bolat et al., ${ }^{14}$ where the risk of polycythemia was shown to be 12.6-fold higher in babies of hypertensive mothers compared to the general population, and it was proven that maternal hypertension constituted a significant risk for polycythemia independent of fetal. ${ }^{14}$ No significant differences regarding $\mathrm{MCV}, \mathrm{MCH}$, and $\mathrm{MCHC}$ between patients and controls however, some authors growth. ${ }^{13}$ It has been reported that normoblasts increase in babies of preeclamptic mothers and this is secondary to uteroplacental hypoperfusion reported high different results. ${ }^{15}$ WBCs values were lower in both preterm and fullterm neonates of preclamptic mothers compared to healthy ones. Preclampsia is known to be a risk factor for neonatal neutropenia and thus for infections in premature newborns. ${ }^{16}$ Leucopenia and neutropenia had been proved in many reports. ${ }^{14,17,18}$ Several mechanisms has been postulated for explanation of leucopenia in that group of babies. Reduced levels of growth factors that are responsible for increase neutrophil production together with presence of inhibitors decrease neutrophil production. ${ }^{19}$ The activity of colony stimulating factor has been shown to be reduced at the placenta of hypertensive mother also fas-fas ligand interaction was reported to be associated with leucopenia in pre-eclampsia. ${ }^{20}$ Also, shifting of hemopoesis under the direct effect of hypoxia towards erythrpeosis rendering less number of stem cells available for granulpoesis which leads to development of in adequate granulopoesis and dysgranulopoiesis (Table 4). ${ }^{21}$

Table 4 Comparison between term and preterm preeclampsia according to infant data

\begin{tabular}{llll}
\hline Variables & $\begin{array}{l}\text { Term } \\
\text { preeclampsia }\end{array}$ & $\begin{array}{l}\text { Preterm } \\
\text { preeclampsia }\end{array}$ & p-value \\
\hline Birth weight $(\mathrm{kg})$ & $2.2 \pm 0.2$ & $1.8 \pm 0.2$ & $0.00 \mathrm{I}^{*}$ \\
APGAR I & $7.7 \pm 0.8$ & $6.5 \pm 0.7$ & $0.00 \mathrm{I}^{*}$ \\
APGAR 5 & $8.3 \pm 0.6$ & $7.5 \pm 0.9$ & $0.00 \mathrm{I}^{*}$ \\
Hb (gm/ml) & $16.2 \pm 0.9$ & $16.6 \pm 1.1$ & 0.2 \\
RBCs (I06/ml) & $4.6 \pm 0.4$ & $4.7 \pm 0.4$ & 0.5 \\
WBCs (I03/ml) & $10.7 \pm 2.1$ & $10.8 \pm 2.2$ & 0.8 \\
Platelets (I05/ml) & $186.1 \pm 91.5$ & $133.7 \pm 58.9$ & $0.00 I^{*}$ \\
PT (seconds) & $28.03 \pm 6.9$ & $21.7 \pm 3.1$ & 0.001 \\
PC (\%) & $43.2 \pm 7.8$ & $6 I \pm 7.7$ & 0.001 \\
PTT (seconds) & $52.7 \pm 6.7$ & $51.2 \pm 7.9$ & 0.45 \\
\hline
\end{tabular}

$\mathrm{Hb}$, hemoglobin; RBCs, red blood cells, WBCs, white blood cells; PT, prothrombin time; $\mathrm{PC}$, prothrombin concentration; $\mathrm{PTT}$, partial thromboplastin time; *, significant $(p<0.05)$.
Regarding platelet count, they were significantly decreased in the study group (both preterm and full term) when compared with control group $(p=0.001)$. Purnima Meher et al., ${ }^{22}$ proved higher incidence of thrombocytopenia in newborns of preeclamptic mothers compared to the newborns of normotensive mothers. Thrombocytopenia could occur as a result of thrombocyte adherence to the damaged endothelial region caused by segmental vasospasm and vasodilatation in the placenta of hypertensive mothers. ${ }^{14}$ Significant higher prothrombin time (PT) and lower prothrombin concentration (PC) where found in neonates of preeclamptic mothers compared to controls $(p=0.001$ for both). This agrees the results of MosayebiZ et al., ${ }^{23}$ who reported PT and PTT were abnormally prolonged in $7.1 \%$ and $27.3 \%$ of their patients respectively. ${ }^{23}$ Development of DIC despite of vitamin $\mathrm{k}$ administration at the time of delivery, hepatic immaturity and impairment of balance between coagulating and fibrinolysis at utroplacental circulation can explain such findings. ${ }^{24,25}$ Regarding the maturity status preterm babies to preeclamptic mothers were found to have more compromise in their coagulation panel. Immaturity of the liver and haemostatic system could be the major cause. Narayan et al and Olox et al had reported similar results and they attribute their results to sever vitamin $\mathrm{k}$ deficiency in preterm ones.

\section{Conclusion}

Hypertension during pregnancy has direct effect on the newborn of affected mother producing several mortalities and mortifies, one of these complication is alteration of hemobiotic system and coagulation profile rendering the babies at risk of bleeding and increased susceptibility to infection due to reduction of platelets number and impaired coagulation profile. preterm baby has proven to be more affected than full term .all these findings need good antenatal care and resuscitation facilities and carful follow up of hematological and coagulation status for this group of babies.

\section{Acknowledgments}

None.

\section{Conflicts of interest}

The author declares there are no conflicts of interest.

\section{References}

1. Cunningham FG, MacDonald PC, Gant NF. Hypertensive disorders in pregnancy. In: Cunningham FG, MacDonald PC, editors. Williams Obstetrics. Prentice Hall, Norwalk 1989; 653-694.

2. Andrea G. Within, Sibai BM. Hypertension in pregnancy: current concepts of preeclampsia. Ann Rev Med. 1997;48:115-127.

3. Cunningham, Leveno, Bloom, Hauth, Rouse, William's Obstetrics. Hypertensive disorders of Pregnancy. 23rd ed. McGraw Hill; 2010. p. 693-694.

4. Nelson S, Greer I. Hypertensive disorders of pregnancy. Preventative, immediate and long-term management. Exp Rev of Pharmaco and Outcomes Research. 2006;6(5):541.

5. Philip Steer, Martin Lupton. Rennie and Robertson's textbook of neonatology. 4th ed.. Churchill Livingstone; 2005.

6. Eugene Oteng-Ntim. Hypertensive diseases in pregnancy. 179-181. 5. p.

7. Yucesoy G, Ozkan S, Bodur H, et al. Maternal and perinatal outcome in pregnancies complicated with hypertensive disorder of pregnancy: a seven year experience of a tertiary care center. Arch Gynecol Obstet. 2005;273(1):43-49. 
8. Dekker, BM Sibai. Etiology and pathogenesis of preeclampsia: current concepts. American Journal of Obstetrics and Gynecology. 1998;179(5):359-1375.

9. Friedman SA, Schiff E, Kao L, et al. Neonatal outcome after preterm delivery for preeclampsia. American Journal of Obstetrics and Gynecology. 1995;172(6):1785-1792.

10. Schola Catarino C, Rebelo I, Belo L, et al. Umbilical cord blood changes in neonates from a preeclamptic pregnancy. From Preconception to Postpartum. 2012:269-287.

11. Kalagiri RR, Choudhury S, Carder T, et al. Neonatal thrombocytopenia as a consequence of maternal preeclampsia. Am J Perinatol Rep. $2016 ; 6: 42-47$.

12. Management of Severe Preeclampsia and eclampsia; Guidelines and Audit Implementation Network: 2012.

13. Lin S, Leonard D, Co MA, et al. Pre-eclampsia has an adverse impact on maternal and fetal health. Transl Res. 2015;165(4):449-463.

14. Sibai BM. Hypertension in pregnancy. In: Gabbe SG, Niebly JR, Simpson JL, editors. Obstetrics Normal \& Problem Pregnancies. Churchill Livingstone; 1996. p. 935-987.

15. Catarino C, Rebelo I, Belo L, et al. Erythrocyte changes in preeclampsia: relationship between maternal and cord blood erythrocyte damage. $J$ Perinat Med. 2009;37:19-27.

16. Heilmann L, Rath W, Pollow K. Fetal hemorheology in normal pregnancy and severe preeclampsia. Clin Hemorheol Microcirc. 2005;32:183-190.

17. Manroe BL, Weinberg AG, Rosenfeld CR, et al. The neonatal blood count in health and disease. I Reference values for neutrophilic cells. $J$ Pediatr. 1979;95(1):89-98.
18. Prakash PL, Sunil kumar P, Venkata Murthy M, et al. Assessment of haematological profile of new-born at birth born to mothers with gestational hypertension, preeclampsia and eclampsia syndrome. $J$ of Evolution of Medi and Dent Sciences. 2013;34:6360-68.

19. Koenig JM, Christensen RD. The mechanism responsible for diminished neutrophil production in neonates delivered of women with pregnancy induced hypertension. Am J Obstet Gynecol. 1991;165:467-473.

20. Kuntz TB, Christensen RD, Stegner R, et al. Fas and Fas ligand expression in maternal blood and umbilical cord blood in preeclampsia. Pediatr Res. 2001;50:743-749.

21. Moallem M, Koenig JM. Preeclampsia and neonatal neutropenia. Neo Reviews. 2009;10:454-459.

22. Purnima Meher, Sitanshu Kumar Meher, Sunil Kumar Jena. Cord blood parameters change in pregnancy induced hypertension. International Journal of Research in Medical Sciences. 2017;5:5.

23. Mosayebi Z, Nariman S, Hosseini L, et al. Evaluation of Laboratory Disorders in Admitted Neonates in NICU Who Were Born to Preeclamptic Mothers. J Compr Ped. 2013;4(4):194-199.

24. Narayan S, Kumari S, Mangwana S, et al. Consumption coagulopathy in neonates born to mothers with pregnancy induced hypertension. Indian Pediatr. 1994;31(7):840-842.

25. Olox CD, Word RA, Corrigan JJ. Effects of preeclampsia on materna and cord blood clotting activity. Am J Perinatol. 1985;2(4):279-282. 